\title{
Semblanzas
}

\section{Delia Argentina Deli $1931-2016$}

Delia Deli dedicó la mayor parte de su vida a la enseñanza de la lengua griega. Obtuvo su título de maestra en la Escuela Normal № 7 "José María Torres" en 1948 e inmediatamente después ingresó a la Facultad de Filosofía y Letras de la UBA, en la que se graduó en 1953 con Diploma de Honor. Fue allí discípula de Guillermo Thiele. Al poco tiempo obtuvo un cargo de auxiliar docente de Trabajos Prácticos del entonces Departamento de Lingüística y Literaturas Clásicas de la Facultad, institución en la que llegó a ser Profesora Titular con dedicación exclusiva desde el año 1983, luego de desempeñarse durante varios lustros como Profesora Adjunta a cargo de cátedra. Llegó a ser Directora del Departamento de Lenguas y Literaturas Clásicas en el período 1997-1998, hasta su alejamiento de las tareas docentes en marzo de 1999. En la Facultad de Medicina de la Universidad de Buenos Aires fue traductora honoraria del Instituto de Historia de la Medicina (1961) y colaboradora del curso de Historia de la Ciencia (1962). Ejerció la docencia secundaria en la Escuela Nacional de Educación "Otto Krause", en la Escuela Industrial № 1 de Avellaneda y en el Instituto adscripto "Luis A. Huergo". En 1967 se especializó en Filología Micénica y Papirología en la Facoltà di Lettere e Filosofía, Università degli Studi di Roma. También fue socia fundadora de la Asociación Argentina de Estudios Clásicos (AADEC). Publicó varios artículos de su especialidad; mencionamos los aparecidos en esta revista: "Algunas incógnitas de la ecuación Eurípides-Aristófanes" (1977) y "La transformación de la tradición épica en la Hécuba de Eurípides" (1991-1992).

Más allá de estos datos queremos destacar el notable compromiso de Delia Deli con la enseñanza de la lengua, que hizo de ella una docente ejemplar y formadora de ayudantes de cátedra. Quienes tuvimos el privilegio de ser sus alumnos y, luego, de trabajar con ella, recordamos su obsesión por el temor de que los alumnos "perdieran" una clase si alguno de nosotros se ausentaba, pues para ella era prioritario el beneficio del estudiante. Se presentaba en las clases prácticas de los auxiliares, a quienes sustituía si era necesario, observaba minuciosamente el desarrollo de los temas y al 
finalizar la hora, amablemente pero sin vacilar, señalaba los defectos que había notado con el fin de mejorar la tarea pedagógica. En las frecuentes reuniones de cátedra era notable su desvelo por lograr el máximo rendimiento de alumnos y docentes. Era minuciosa en la elaboración de fichas de cátedra y de exámenes parciales, en los que valoraba todos los detalles. Se actualizaba en bibliografía y ediciones de autores como asimismo en los enfoques teóricos de la literatura. Los tiempos actuales, en los que la enseñanza presenta flaquezas y puntos débiles, hacen que uno extrañe la presencia de Delia Deli en la Facultad.

Diana Frenkel Universidad de Buenos Aires 